\title{
A SYSTEMATIC SCOPING REVIEW ON SKILLS VARIETY FOR VET IN THE INDUSTRY 4.0
}

\author{
Francesco Tommasi, Ioris Franceschinis, Marco Perini, \& Riccardo Sartori \\ Department of Human Sciences, University of Verona (Italy)
}

\begin{abstract}
In the wake of the 4th industrial revolution, the prospects about new jobs and workers' skills, and competence appear to be uncertain. There is a large agreement about the view of the current revolution as characterized by an embedded exponential evolution which will affect the labor transformation as well as future workers' curriculum. Therefore, researchers and practitioners in the field of vocational and educational training (VET) are questioning about which skills and abilities will be the core of the third-millennium jobs 'profiles. Accordingly, the present poster intends to present the results of a systematic scoping review in order to offer a knowledge-based description of VET in the 4.0 industry. By the use of this method among three main databases, the contribution purposes a synthesis of $n=13$ items by which three classes of competences emerged, namely, scientific-, transversal- competences, and technical skills. All of these classes resulted to be relevant for the futuristic workers to compete in the diverse, and plural world of the 4th revolution of work. Moreover, the present paper offers possible applied implications in VET sectors of training and development as well as a forward perspective for human resources management.
\end{abstract}

Keywords: Industry 4.0, competences profile, systematic review, VET.

\section{Introduction}

The last decade has been characterized by the huge impact of technological progress in all the working sectors leading to an exponential evolution of work. The recent changes regard the so-called $4^{\text {th }}$ industrial revolution - or industry 4.0 - commenced through the preliminary introduction of artificial intelligence and automation in many different working sectors. Conceptually, the current revolution builds on the progress of the $3^{\text {rd }}$ industrial revolution marked by the digitalization process, whose spread and velocity of changes are its core aspects. It has a global impact disrupting all the working sectors, systems and working level. In this vein, looking to the implications of industry 4.0 for market industry, VET researchers and practitioners, are questioning about how and to what extent the industry 4.0 will affect workers profile curriculum. More precisely, there's a lack of a comprehensive view about how to sustain and support workers and organization in terms skills and abilities needed for the third-millennium jobs 'profiles (Loveder, 2017; Moldovan, 2019; WEF, 2019).

The goal of the present paper is to try to propose an answer to the questions about how to provide forward workers with sufficient competences and skills needed in the wake of the industrial revolution. Therefore, the contribution intends to present the preliminary results of a systematic scoping literature review in order to answer the following questions:

- In the wake of the $4^{\text {th }}$ industrial revolution, which competencies are required by workers to deal with the automation and digitalization of work processes?

- What are the core aspects of VET trainers and practitioners in order to sustain workers profile curricula in the industry 4.0 ?

The article consists of three main sections. Firstly, the method of the systematic scoping review is presented as well as the data collection procedure according to the research questions. Then, results are presented in the second section followed by the discussion in the last section.

\section{Method and data collection}

Briner and Deyner (2012) argued that a systematic review can constitute an opportunity for theory and research. It helps to summarize the literature around a specific topic and to create a comprehensive synthesis which can help researchers and practitioners in the field of work and organizations. According to the research questions, the present paper authors referred to the line-guides of Briner and Deyner in order to propose a tentative answer to questions on competencies and skills for Industry 4.0 workers. Notwithstanding the word systematic, these line-guides suggest that a systematic review in the field of research about work and organization turns to broaden principles rather than strict procedures in order to propose a coherent and organized state of the art about a specific subject. 
Moreover, Briner and Denyer (2012) argued that in the synthesis process, authors can consider a methodology based on the aims of the literature review. In this vein, the scoping synthesis process (Arksey \& O'Malley, 2005) offers a useful way to interpret the results. Arksey and O'Malley (2005) argued that the scoping synthesis focuses on topics and sub-topics of contribution extracted by the literature review and it aims at finding the relations between themes in order to map the knowledge around the topic.

Following the methodology presented, the literature review commenced with the keywords extraction for data collection within the academic databases of Scopus, Web of Science and Eric. By the combination of words as "Competence", "Industry 4.0", VET" and linked words, the first stage collected $n=1,199$ items which have been analyzed by the researchers according to the criteria developed. Then, only items published after 2011, in English and within the research field of adult education and vocational education and training, VET have been included $(n=91)$. The extracted items have been analyzed by the three researchers involved in the study which used a specific form of analysis consisting on three main questions about (a) the relevance of the item, (b) the quality of the item, and (c) the coherence with the research questions. By this process, $n=13$ items were included for the synthesis process among which, $n=4$ items are literature review, $n=3$ book chapters or research report and $n=4$ official documents produced by international institutions and organizations, e.g., CEDEFOP.

\section{Results}

The three researchers worked individually in order to syntheses and interpret all the contributions collected referring to the themes and topics discussed. Then, they compared they result in order to propose a final comprehensive view of the contributions extracted. Two main topics emerged during the synthesis process. Firstly, authors of the items extracted agreed about the definition of industry 4.0 as the result of the current industrial revolution, characterized by an embedded exponential evolution which will affect the labor transformation as well as future workers' curriculum. Secondly, the workers of the third millennium will need of mix competences combining scientific knowledge and soft skills. In fact, by the comparison of each syntheses, the three researchers agreed to consider three main classes of competences, namely, scientific-, transversal- competences, and technical skills. In the present section the core aspects of each classes will be presented in the view of the VET sector.

\subsection{Classes of competence for industry 4.0 in VET sector}

Scientific and technological competence: the first class of competence regards the group of scientific, technological, engineering and mathematical knowledge (Moldovan, 2019; Molla \& Cuthbert, 2019; Payton, 2017; Plutenko, Leyfa, Kozyr, \& Haletskaya, 2018; VET 4.0, 2019). Authors presented these competences referring to higher levels of qualification learned in higher education programs. Mainly, this class of competences regards the ability to data analysis and data scientists, and besides, the knowledge needed for technological innovation and artificial intelligence. Therefore, this class of competence is more linked to specific jobs and roles in organization although authors discussed their relevance logical thinking and problem solving linked to STEM even for those workers who have different roles and job tasks (Cedefop, 2018; Loveder, 2017; Payton, 2017; Plutenko et al., 2018; Pfeiffer, 2018).

Technical and digital abilities: The second class regards the technical and digital abilities and the know-how of workers. These represent a significant broad class of abilities related the new job places. On the one hand, organizations and smart industries will need workers able to deal with the automated systems in terms of maintenance and repair. In fact, all the machines that will implement the industry will need the human interaction for their functioning in order to reduce the costs and increase the production. (Fraser et al.,2019; Huang \& Chang, 2011; Sangmeister, et a., 2018). Moreover, all the organizational figures involved at the level of organization will need to be able to deal with data management and digital systems. In this vein, all the professional figures need a sufficient knowledge to address the constant evolution of artificial systems (Avis, 2018; Winterton \& Turner, 2019; Umachandran, \& Della Corte 2019)

Transversal Competence: The last class emerged as a comprehensive class of all the aspects discussed within the contributions that do not refer to the class of scientific competences and digital abilities. In fact, some authors reported the relevance of (a) interpersonal skills for team climate and team building, others presented (b) the ability to react to current in process and resist emphasizing the emotional competences as well as (c) the self-agency for life-long learning (ILO, 2017; Moldovan, 2019; VET 4.0, 2019; Umachandran, \& Della Corte 2019). What twist and turn will take the industry 4.0 is still a contested debate to which authors are not able to give a sufficient answer. However, all the contributions analysed sustained and promoted a positive point of view with which human-interaction technology is seen as an opportunity for workers to develop new job profile and knowledge as well as to invest in interpersonal relations and personal development (Symon \& Whiting 2019). 


\section{Discussion}

In the wake of the industry 4.0, the VET practitioners and researchers are called to sustain and promote the workers' curriculum of the future. In this term, the present analysis of the literature have found a possible framework to classify the abilities and competences according to the different job sectors. In fact, answering to research questions, our aim was to propose a comprehensive view of the literature in order to (a) shed light around the subject of competences for the industry 4.0 and (b) to propose a possible framework for training programs.

As seen, the mix of competence calls for a deep attention to the job sectors and role aspects. In this vein, practitioners and researchers need to understand the characteristics in order to turn the training programs according the different needs of workers and organizations. In contrast, the class of transversal competences support the large need of soft skills and interpersonal competences. Among all the reviewed items, a common agreement regarding the necessity to provide sufficient support to people relations and internal aspects as the ability to adapt to the current changes and to deal with the new technologies.

Finally, the present literature review has inevitably some limitations. Although the method used is sustained in literature and largely used, only a few contributions have been extracted and analyzed and we are not sure if there any other relevant contributions. Forward research could try to investigate devising more inclusive criteria as well as including empirical examination of the evidence produced by the literature review.

\section{References}

Arksey, H., \&amp; O’Malley, L. (2005). Scoping studies: Towards a methodological framework. International, Journal of Social Research Methodology: Theory and Practice, 8(1), 19-32.

Avis, J., 2018. "Socio-Technical Imaginary of the Fourth Industrial Revolution and Its Implications for Vocational Education and Training: A Literature Review." Journal of Vocational Education \& Training 70(3): 1-27.

Briner, R. B., \&amp; Denyer, D. (2012). Systematic Review and Evidence Synthesis as a Practice and Scholarship Tool. The Oxford Handbook of Evidence-Based Management $\left(1^{\text {st }} \mathrm{Ed}\right)$.

CEDEFOP, 2018. Insights into Skill Shortages and Skill Mismatch: Learning from Cedefop's European Skills and Jobs Survey. Luxembourg.

Huang, C., Y., \& Chang C., C., 2011. "Defining the VET Policy Instruments for Developing the National Innovation System of Fuel Cell Technologies." 2011 IEEE Green Technologies Conference, Green 2011: 1-6.

ILO. 2017. Skills Needs Anticipation: Systems and Approaches. Analysis of Stakeholder Survey on Skill Needs Assessment and Anticipation.

Loveder, P., 2017. "Australian Apprenticeship: Trends, Challenges and Future Opportunities for Dealing with Industry 4.0.” In Adelaide, 1-38.

Moldovan, L. 2019. "State-of-the-Art Analysis on the Knowledge and Skills Gaps on the Topic of Industry 4.0 and the Requirements for Work-Based Learning." Procedia Manufacturing 32: 294-301.

Molla, T., \& Cuthbert D., 2019. "Calibrating the PhD for Industry 4.0: Global Concerns, National Agendas and Australian Institutional Responses." Policy Reviews in Higher Education 3(2): $167-88$

Payton, A., 2017. "Skilling for Tomorrow." In 26th National VET Research Conference 'No Frills,' Adelaide: National Centre for Vocational Education Research, 1-7.

Pfeiffer, S., 2018. "The 'future of Employment' on the Shop Floor: Why Production Jobs Are Less Susceptible to Computerization than Assumed." International Journal for Research in Vocational Education and Training 5(3): 208-25.

Plutenko, A., D., Leyfa, A., V., Kozyr A., V., \& Haletskaya, T., V., 2018. "Specific Features of Vocational Education and Training of Engineering Personnel for High-Tech Businesses." European Journal of Contemporary Education 7(2): 360-71.

Sangmeister, J., et al. 2018. "Designing Competence Assessment in VET for a Digital Future." In Digital Workplace Learning, Cham: Springer International Publishing, 65-92.

Symon, G., and Whiting R., 2019. "The Sociomaterial Negotiation of Social Entrepreneurs' Meaningful Work.” Journal of Management Studies 56(3): 655-84.

Umachandran, K., \& Della Corte V., 2019. "Designing Learning-Skills towards Industry 4.0." World Journal on Educational Technology 11(2): 23

VET 4.0. 2019. The $4^{\text {Th }}$ Industrial Revolution in Business Introduction to the VET provision.

WEF. 2019. Cambiamenti Nel Mondo Del Lavoro. Banca Internazionale per la Ricostruzione e lo Sviluppo.

Winterton, J., \& Jason J., T., 2019. "Preparing Graduates for Work Readiness: An Overview and Agenda." Education \& Training 61(5): 536-51. 